\title{
DIPEPTIDYL PEPTIDASE-4 INHIBITORS: POTENTIAL FOR TREATMENT OF METABOLIC SYNDROME AND DEVELOPED FORMULATION APPROACHES
}

\author{
RAKESH MISHRA ${ }^{1 *}$, SHASHIKANT DHOLE ${ }^{2}$ \\ ${ }^{1}$ Department of Pharmaceutics, Dr. D. Y. Patil Institute of Pharmaceutical Sciences and Research, Pimpri, Pune - 411 018, Maharashtra, \\ India. ${ }^{2}$ Department of Pharmaceutics, Modern College of Pharmacy, Moshi, Pune - 412 105, Maharashtra, India. \\ Email: mishrarakesh287@gmail.com \\ Received: 30 May 2017, Revised and Accepted: 29 July 2017
}

ABSTRACT

This review article deals with the pre-clinical and clinical findings reviewed or investigated by the researchers on dipeptidyl peptidase-4 (DPP4) inhibitors as a potential in the treatment of metabolic syndrome. Most of the researchers reported the activity of DPP4 inhibitors in the management of obesity, hyperlipidemia, hypertension, atherosclerosis, and in cardiometabolic risk which are summarized in the article. This article also focuses on the formulation approaches in which the formulators have reported and used in the designing or development of DPP4 inhibitors as dosage form. The formulation approaches which are commonly employed on DPP4 inhibitors are immediate release, sustain release, and combination therapy.

Keywords: Dipeptidyl peptidase 4, Metabolic syndrome, Obesity, Hyperlipidemia, Hypertension, Atherosclerosis, Immediate release, Sustain release. (c) 2017 The Authors. Published by Innovare Academic Sciences Pvt Ltd. This is an open access article under the CC BY license (http://creativecommons. org/licenses/by/4. 0/) DOI: http://dx.doi.org/10.22159/ajpcr.2017.v10i11.20342

\section{INTRODUCTION}

The lives of far too many in the world are being blighted due to urbanization, sedentary lifestyles, and changing diets. These characteristic factors of $21^{\text {st }}$ century leads to risk for developing a number of chronic diseases such as insulin resistance, obesity, dyslipidemia, hypertension, and cardiometabolic risk. This has led to the concept of "The Metabolic Syndrome" which includes clusters of these chronic diseases observed in patients [1]. As defined by the American Heart Association, metabolic syndrome includes the presence of at least three of the following five conditions: (1) Abdominal obesity (waist circumference $\geq 40^{\prime \prime}$ if male or $\geq 35^{\prime \prime}$ if female), (2) high blood pressure (systolic $\geq 130 \mathrm{~mm} / \mathrm{Hg}$ or diastolic $\geq 85 \mathrm{~mm} / \mathrm{Hg}$, (3) low- and high-density lipoprotein cholesterol ( $<40 \mathrm{mg} / \mathrm{dL}$ if male or $<50 \mathrm{mg} / \mathrm{dL}$ if female), (4) high triglycerides ( $\geq 150 \mathrm{mg} / \mathrm{dL}$ ), and/or (5) high blood glucose ( $\geq 100 \mathrm{mg} / \mathrm{dL}$ ) [2]. The prevalence of metabolic syndrome increases at an alarming rate and is becoming a major public health concern. Individuals with metabolic syndrome have a high risk of morbidity and mortality due to cardiovascular disease (CVD) and type 2 diabetes [3]. In view of this, to manage and treat metabolic syndrome various efforts have been made from raising awareness about lifestyle changes to the discovery and development of safe and effective medications. However, patient compliance becomes an issue in the management of metabolic syndrome when multiple drugs need to be taken on a long-term basis in the treatment of multifactorial diseases. In addition, there is the risk of enhanced drug-drug interactions when multiple drugs are prescribed. Identifying drug candidates exhibiting polypharmacology could be one of the strategies beneficial to address multifactorial diseases as indicated in Table 1. As a consequence, availability of a single therapeutic agent which would simultaneously ameliorate the pharmacological processes contributing to multifactorial diseases could be a significant step forward in the treatment of metabolic syndrome [4].

Dipeptidyl peptidase 4 (DPP4) enzymatic inhibitors a widely accepted oral therapy for the management of type 2 diabetes mellitus (T2DM), were first developed as antidiabetic agents which preserve incretin hormones and promote post-prandial insulin secretion [5]. In the past few years, numerous pre-clinical and clinical trials have demonstrated that DPP4 inhibitors besides their glucose-lowering activity could be used in the management of multifactorial diseases constituting metabolic syndrome (Fig. 1).

DPP4 is a serine protease that is widely distributed throughout the body, expressed as an enzyme on endothelial cells, the surface of T-lymphocytes, and in a circulating form [6,7]. As a membranespanning, cell-on surface aminopeptidase, it is ubiquitously expressed in many tissues, such as the gut, lymphocyte, liver, kidney, and lung. DPP4 inhibitors competitively inhibit the enzyme DPP4, this enzyme breaks down the incretin glucagon-like peptide-1 (GLP-1) and glucose-dependent insulinotropic peptide, which are released in response to a meal [8]. DPP4 inhibitors may be classified into peptidomimetic (i.e., sitagliptin, teneligliptin, vildagliptin, saxagliptin, and anagliptin) and non-peptidomimetic (i.e., alogliptin and linagliptin) subtypes. Sitagliptin was the first gliptin approved by the Food and Drug Administration (FDA) of the United States in October 2006 and is now available worldwide. Vildagliptin and saxagliptin were approved by the FDA in between February 2008 and July 2009, respectively. Alogliptin was approved by the Pharmaceuticals and Medical Devices Agency (PMDA) of Japan in April 2010 and by the FDA in January 2013. Anagliptin is available only in Japan since it was approved by the PMDA in September 2012, and linagliptin was authorized by the FDA in May 2011. Gemigliptin was codeveloped by LG Life Science and DoubleCrane Pharmaceutical Co. and gained approval from the Korea Food and Drug Administration in June 2012 [9]. The review focuses on the potential of DPP4 inhibitors in the management of metabolic syndrome as well as the formulation approaches employed on DPP4 inhibitors in the development of dosage form. The review provides further light on the potential benefits of DPP4 inhibitors beyond those based on glycemic control.

DPP4 inhibitors in the treatment of metabolic syndrome This section covers the discussion on the pre-clinical and clinical findings reviewed or investigated by the researchers on DPP4 inhibitors as a potential in the treatment of metabolic syndrome. As most of the researchers reported the activity of DPP4 inhibitors in management of obesity, hyperlipidemia, hypertension, atherosclerosis, and in cardiometabolic risk which are summarized as follows. 
Table 1: DPP4 substrates and probable inhibitory effects for the management of metabolic syndrome

\begin{tabular}{|c|c|c|}
\hline DPP4 substrates & Biological function of substrates & $\begin{array}{l}\text { Impact of DPP4 inhibition on } \\
\text { multifactorial diseases }\end{array}$ \\
\hline $\begin{array}{l}\text { Incretin hormones } \\
\text { Glucagon-like peptide-1 (GLP-I) } \\
\text { Glucose-dependent insulinotropic peptide (GIP) }\end{array}$ & $\begin{array}{l}\text { GLP-I: Stimulate insulin secretion and suppress } \\
\text { glucagon release } \\
\text { Regulator of satiety and appetite } \\
\text { GIP: Stimulates insulin secretion and promotes fatty } \\
\text { acid metabolism }\end{array}$ & $\begin{array}{l}\text { Type-II diabetes mellitus, } \\
\text { hyperlipidemia/obesity }\end{array}$ \\
\hline $\begin{array}{l}\text { Neuropeptides } \\
\text { NPY } \\
\text { Peptide YY } \\
\text { Brain natriuretic peptide (BNP) }\end{array}$ & $\begin{array}{l}\text { NPY: Regulates energy balance, memory, learning, and } \\
\text { lipid metabolism } \\
\text { Peptide YY: Reduces appetite, inhibits gastric motility, } \\
\text { and increases water and electrolyte absorption in the } \\
\text { colon }\end{array}$ & Hyperlipidemia/obesity \\
\hline & $\begin{array}{l}\text { BNP: Responsible for vasodilation, natriuresis and } \\
\text { suppresses rennin secretion }\end{array}$ & Cardiometabolic risk/hypertension \\
\hline $\begin{array}{l}\text { Chemokines } \\
\text { Stromal cell-derived factor-1 (SDF-1) }\end{array}$ & SDF-1: Promotes angiogenesis & Cardioprotective \\
\hline
\end{tabular}

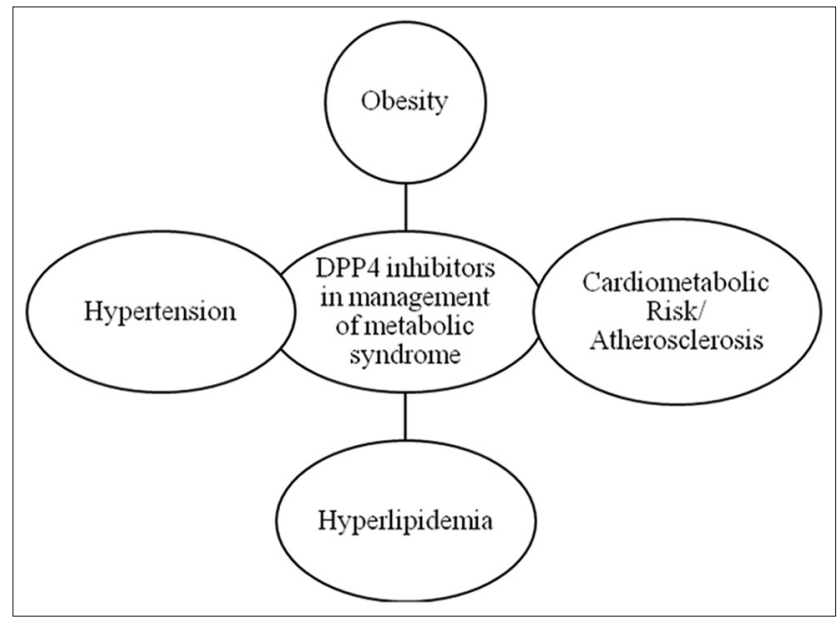

Fig. 1: Dipeptidyl peptidase 4 inhibitors in multifactorial diseases

\section{DPP4 inhibitors in the management of obesity}

Overweight and obesity are serious problems, especially in industrialized countries, since they have impact on disease development and quality as well as expectancy of life [10]. Understanding the complex mechanisms regulating energy homeostasis is a keystone for developing novel strategies for obesity therapy [11,12]. Interestingly, several neuropeptides involved in controlling energy homeostasis such as GLP-1, peptide YY, and neuropeptide Y (NPY) are substrates of DPP4 [13,14]. Stephan et al. reported the possible influence of adenosine deaminasecomplexing protein 2 (CD26), exerting a dipeptidyl peptidase activity (DPP4) cleaving several energy homeostasis-relevant peptides, by investigating wild type, and DPP4-deficient dark agouti rats in a model of diet-induced obesity and found a reduced weight gain in DPP4deficient rats. They investigated the number of cells immune positive for the leptin receptor (OB-R), the orexigenic leptin antagonist NPY, as well as of the NPY receptors Y1, Y2, and Y5 within hypothalamic nuclei. Independent from the body weight, higher levels of NPY, and all receptors were expressed in DPP4-deficent rats. Under obese conditions, hypothalamic Y2-levels were reduced in both strains. This study suggested that DPP4 exerts its effects on intra-abdominal fat also through peripheral actions [15]. Matthias reviewed novel pharmacological treatment strategies, which target mechanisms underlying positive energy balance, excessive fat accumulation, and adverse fat distribution. Adipokines may have potential for the future pharmacological treatment strategies of obesity and metabolic diseases, because they are involved in the regulation of appetite and satiety, energy expenditure, endothelial function, blood pressure, insulin sensitivity, adipogenesis, fat distribution, and insulin secretion [16].

DPP4 is a novel adipokine oversecreted in obesity, and thus potentially linking obesity to the metabolic syndrome. DPP4 is a ubiquitously expressed cell surface protease which is also released to the circulation as soluble DPP4. Furthermore, sDPP4 impairs insulin signaling in an autocrine and paracrine fashion in different cell types [17]. Röhrborn et al. investigated the effects where human adipocytes were treated with the DPP4 inhibitors sitagliptin and saxagliptin. Interestingly, DPP4 reduction increase protein kinase B leading to improved insulin responsiveness of adipocytes at the level of insulin receptor [18].

GLP-1, secreted by intestinal L-cells, stimulates glucose-dependent insulin secretion after food ingestion $[19,20]$. GLP-1 enhances satiety, whereas it inhibits glucagon secretion, food intake, and gastric emptying [21]. However, the therapeutic potential of GLP-1 has been demonstrated to be limited due to its rapid degradation and inactivation in vivo by DPP4 [22]. Ben-Shlomo et al. investigated the effects of GLP-1, a gut-derived peptide degraded by DPP4 on hepatic fat and glucose metabolism. Normal- and high-fat diet-fed DPP4 rats displayed reduced hepatic triglycerides, accompanied by downregulation of lipogenesis enzymes, and parallel upregulation of carnitine palmitoyltransferase 1, a key enzyme in fatty acid b-oxidation. In vitro studies demonstrated that GLP-1 suppresses hepatic lipogenesis through activation of the AMPK pathway [23]. Lee et al. investigated KR-66195, a new synthetic DPP4 inhibitor, could prevent weight gain, as well as improving glycemic control in diet-induced obese (DIO) and ob/ob mice. In DIO mice, KR-66195 treatment increased the plasma GLP-1 levels and improved glucose tolerance. This treatment also reduced body weight gain $(5.38 \pm 0.94$ vs. $12.08 \pm 0.55 \mathrm{~g}, \mathrm{p}<0.01)$ and food intake $(2.41 \pm 0.09$ vs. $2.79 \pm 0.11 \mathrm{~g}, \mathrm{p}<0.05)$. Results suggested that KR-66195 prevented weight gain in DIO mice by decreasing food intake, as well as increasing energy expenditure by 16\% [24]. Fukuda-Tsuru et al. investigated the impact of the novel DPP4 inhibitor teneligliptin on body weight, energy expenditure, and obesity-related manifestations in DIO mice. The administration of teneligliptin reduced body weight to $88 \%$ and $71 \%$ at dose of $30 \mathrm{mg} / \mathrm{kg} /$ day and $60 \mathrm{mg} / \mathrm{kg} /$ day, respectively. Adipocyte hypertrophy and hepatic steatosis induced by a high-fat diet were suppressed by teneligliptin. The findings suggested the potential utility of teneligliptin for the treatment of a broad spectrum of metabolic disorders related to obesity beyond glycemic control [25].

A decrease in serum estrogen levels in menopause is closely associated with the development of visceral obesity and the onset of type 2 diabetes in women [26]. Sameshima et al. demonstrated the therapeutic effects of the novel DPP4 inhibitor, teneligliptin, on the features of post- 
menopausal obesity in mice. The metabolic phenotypes body weight, fat accumulation, and glucose intolerance were analyzed and suggested that teneligliptin effectively ameliorates the characteristics of metabolic abnormalities associated with post-menopausal obesity [27].

\section{DPP4 inhibitors in the management of hyperlipidemia}

Clinical trials with DPP4 inhibitors have shown that these agents also show lipid-lowering effects. Meta-analyses showed lipid-lowering effects of several DPP4 inhibitors [28,29]. Aoki et al., evaluated the effect of anagliptin on serum lipid profiles, including cholesterol synthesis and absorption markers, in Japanese patients with type 2 diabetes. Anagliptin therapy decreased the cholesterol synthesis marker lathosterol without changing cholesterol absorption markers [30]. Yano et al. examined the lipid-lowering efficacy of anagliptin in a hyperlipidemic animal model and examined the mechanism of action. Anagliptin treatment significantly decreased the plasma total cholesterol $(14 \%$ reduction, $\mathrm{p}<0.01)$ and triglyceride levels $(27 \%$ reduction, $\mathrm{p}<0.01$ ). The results indicated that the DPP4 inhibitor, anagliptin, exhibited a lipid-lowering effect in a hyperlipidemic animal model, and suggested that the down regulation of hepatic lipid synthesis was involved in the effect [31]

\section{DPP4 inhibitors in the management of hypertension}

DPP4 inhibitors was reported to enhance the phosphorylation of endothelium-derived nitric oxide synthase through the cyclic adenosine monophosphate/protein kinase, a pathway in human coronary artery endothelial cells by possibly augmenting the activity of GLP-1 on the endothelium [32]. Nakagami et al. examined the effects of DPP4 inhibitor teneligliptin on spontaneous hypertensive rat/NDmcr$\mathrm{cp}(\mathrm{cp} / \mathrm{cp}$ ) rats as a model for metabolic syndrome and hypertension, glucose metabolism, and endothelial dysfunction were analyzed. The results demonstrated that long-term treatment with teneligliptin significantly improved endothelial dysfunction and glucose metabolism in a rat model of metabolic syndrome suggesting that teneligliptin treatment might be beneficial for patients with hypertension and/ or diabetes [33]. Recently Sattigeri et al. developed chimeric DPP4/ angiotensin-converting enzyme inhibitors for treating metabolic syndrome by rational de novo synthesis exhibiting polypharmacology to address multifactorial diseases (hyperglycemia, hypertension, and dyslipidemia) [4]

\section{DPP4 inhibitors in the management of atherosclerosis}

Jixin et al. focused the importance of DPP4 and its potential role in cardiovascular physiology and pathology. They indicated that in addition to regulation of post-prandial glycemia, DPP4 may have pleiotropic effects and its inhibition may have a role in the treatment of inflammatory diseases such as atherosclerosis and provides evidence for a robust effect of DPP4 inhibitors in attenuating inflammation and plaque development [34].

Atherosclerosis is one of the major pathological manifestations of diabetic vascular complications, which causes narrowing of arterial walls due to chronic inflammation and endothelial injury. In clinical practice, numerous DPP4 inhibitors are present but no studies have been conducted to compare their antiatherosclerotic effects despite growing evidence of their usefulness in the high-risk population. In view of this, Singh et al. reviewed the antiatherothrombotic effects of DPP4 inhibitors in individuals with atherosclerosis using protective score (PS). Sixty-two published studies collected and were assessed, as per the PS sitagliptin (PS=5) was deduced to have the most prominent influence in protecting against atherosclerosis progression. Linagliptin and saxagliptin had the lowest score (PS=1) [35]. Okuda et al. assessed effects of teneligliptin on soluble P-selectin (sP-selectin), plateletderived microparticles (PDMPs), plasminogen activator inhibitor 1 (PAI-1), soluble E-selectin (sE-selectin), soluble vascular adhesion molecule 1 (sVCAM-1), and adiponectin plasma levels in patients with T2DM. Teneligliptin therapy significantly reduced plasma levels of sPselectin, PDMPs, and PAI-1 while significantly increasing adiponectin levels. sE-selectin and sVCAM-1 levels were significantly decreased only at 6 months. By modulating PDMPs or PAI-1, teneligliptin shows an antiatherothrombotic effect that may be beneficial in the primary prevention of CVD in patients with T2DM [36]. Hirano et al. examined the effect of anagliptin, a DPP4 inhibitor, on atherosclerosis development in the aorta and coronary arteries in a high-cholesterol diet-fed rabbits. Japanese white rabbits were fed either normal chow $(n=8)$ or a diet containing $0.5 \%$ cholesterol $(n=34)$ for 14 weeks. Cholesterol-fed rabbits were given $0.3 \%$ anagliptin or not in drinking water (each $\mathrm{n}=16$ and 18) for 12 weeks. This study suggests that DPP4 inhibitors can exert antiatherogenic actions, especially in early stages of atherosclerosis [37].

\section{DPP4 inhibitors in the management of cardiometabolic risk} The five widely used groups of oral antihyperglycemic agents - biguanides, sulfonylureas, meglitinides, glitazones, and alpha-glucosidase inhibitors - are associated with variable degrees of undesirable or even severe cardiovascular events [38]. The FDA recommended that to establish the safety of a new antidiabetic therapy for T2DM, the manufacturers or sponsors should demonstrate that the new drug will not result in an unacceptable increase in cardiovascular risk [39]. In this context, Fisman and Tenenbaum, reviewed DPP4 inhibitors with emphasis on their capabilities to positively or negatively affect the cardiovascular system. The favorable changes in experimental models include improved endothelial function, reduction of inflammatory markers, oxidative stress ischemia/reperfusion injury, and atherogenesis. In addition, increased adiponectin levels and decreases in lipidemia and blood pressure were reported. Moreover, only with saxagliptin, the rate of hospitalization for heart failure was significantly increased [40].

DPP4 enzymatic inhibitors preserve incretin hormones and promote post-prandial insulin secretion. It has been shown in animal studies that incretin-based therapy has a beneficial effect on cardiovascular disease. Gong et al. studied DPP4 enzymatic inhibitors and summarize the catalytic-dependent and -independent effects of DPP4 inhibition on cardiometabolic disease. The review demonstrated novel non-catalytic functions of DPP4 that may play a role in cardiometabolic disease [5]. Tahara et al. studied the effects of anagliptin, an inhibitor of DPP4 on arterial stiffness evaluated by cardio-ankle vascular index with those of an equipotent glucose-lowering agent, glimepiride in patients with T2DM. This study suggested that anagliptin may exert a beneficial effect on arterial stiffness in patients with T2DM, which is independent of its blood glucose-lowering property. Anagliptin may ameliorate arterial stiffness partly through the reduction of RLP cholesterol and improvement of liver function [41].

\section{Developed formulation approaches on DPP4 inhibitors}

In this section, we have discussed only those formulation approaches which formulators have reported and used in the designing or development of DPP4 inhibitors as dosage form. The formulation approaches which are commonly employed on DPP4 inhibitors are immediate release, sustained release, and combination therapy (Fig. 2) as reported.

\section{Immediate release approach}

Oral route of drug administration is perhaps the most widely accepted route for the delivery of drugs. In oral dosage forms, tablet is the most popular dosage form due to convenience of self-administration, compactness, and easy manufacturing. In many cases, immediate onset of action is required, which is not possible with conventional therapy. To overcome these drawbacks, immediate release dosage form has emerged as alternative oral dosage forms. Immediate drug release dosage forms disintegrate rapidly after administration with enhanced rate of dissolution [42].

\section{Orodispersible and immediate release tablets}

In more recent years, increasing attention has been paid to formulating not only fast dissolving and/or disintegrating tablets that are swallowed but also orally disintegrating tablets that are intended to dissolve 


\begin{tabular}{|l|l|}
\hline \begin{tabular}{|l|} 
Immediate Release \\
Approach
\end{tabular} & $\begin{array}{l}\text { - Oro dispersive tablet } \\
\text { - Immediate release tablet }\end{array}$ \\
\hline $\begin{array}{l}\text { Sustained Release } \\
\text { Approach }\end{array}$ & $\begin{array}{l}\text { : Matrix tablet } \\
\text { - Gastroretentive tablets/Microspheres } \\
\text { - Multiparticulate microspheres }\end{array}$ \\
\hline $\begin{array}{l}\text { Combination Therapy } \\
\text { - Multi layer tablets } \\
\text { - Multi unit particulate system (MUPS) }\end{array}$ \\
\hline
\end{tabular}

Fig. 2: Developed formulation approaches on dipeptidyl peptidase-4 inhibitors

and/or disintegrate rapidly in the mouth [43,44]. Iswariya et al. developed orodispersive tablets of saxagliptin using various individual concentrations of super disintegrating agents (crosscarmellose sodium, sodium starch glycolate (SSG), and crospovidone XL 10). This study suggested that the formulation containing $4 \%$ of crospovidone XL 10 was found to be better formulation in terms of rapid disintegration and maximum percentage drug release [45]. Debnath et al. formulated linagliptin immediate release tablets using various superdisintegrants. Based on the dissolution studies, optimized formulation contains $6 \%$ crospovidone produced rapid and highest dissolution rate and dissolution efficiency among all the formulations [46]. The dissolution of linagliptin from the tablets obeyed first-order kinetics. Shakya designed and evaluated sitagliptin phosphate immediate release $50 \mathrm{mg}$ tablet using response surface methodology employing Minitab16. Different formulations of immediate release were prepared by applying 2-factor 2-level central composite design. The amount of SSG and croscarmellose sodium (CCS) in IR layer was used as independent variables, and the percent drug release at 15 minutes were selected as dependent (response) variables for optimization. The optimized sitagliptin phosphate IR tablet disintegrated in 14 seconds and showed an initial release of sitagliptin $99.072 \%$ within 15 minutes [47]. Wale et al. formulated immediate release tablet of sitagliptin phosphate monohydrate by wet granulation method using microcrystalline cellulose, lactose as diluents, crospovidone, and SSG as superdisintegrant. This study concluded that combination of high concentration of crospovidone and low concentration of SSG provides optimum disintegration of sitagliptin phosphate tablet [48].

\section{Sustained release approach}

Sustained release dosage forms are designed to achieve prolonged therapeutic effect by continuously releasing medication over an extended period after administration of single dose. The goal in designing oral sustained delivery system is to reduce the frequency of the dosing or to increase effectiveness of the drug by localizing at the site of action, reducing the dose required or provide uniform drug delivery, thereby also improving patient compliance [49].

\section{Matrix approach for sustained release}

Matrix tablets are the promising approach for the development of sustained and controlled-release solid dosage forms in lowest cost. Matrix tablets may be defined as the "oral solid dosage forms in which the drug or active ingredient is homogeneously dispersed throughout the hydrophilic or hydrophobic matrices which serves as release rate retardants." These systems release drug in continuous manner by dissolution-controlled and diffusion-controlled mechanisms [50,51]. Kolli et al. formulated and evaluated vildagliptin sustained release matrix tablets by wet granulation method using hydrophilic polymers such as HPMC (K15M, K100M) and Carbopol. Drug release follows zero-order release kinetics, and release rate was controlled by nonFickian diffusion. The maximum drug release was found to be $98.78 \%$ over 24 hrs in HPMC K100M and Carbopol-based tablets [52]. Kumar et al. designed and developed the sustained release matrix tablets of vildagliptin by wet granulation technique, using HPMC-K15M, HPMC-K100, sodium alginate, chitosan, xanthan gum, and guar gum. The drug to polymer ratio 1:1 (vildagliptin:xanthan gum) reported optimized shown maximum drug release $97.56 \pm 0.72 \%$ in $12 \mathrm{hr}$ of dissolution [53]. Martha et al. developed sustained release matrix tablets of gemigliptin using HPMC K4M and Carbopol as rate controlling polymers in different concentrations. The optimized formulation prepared with drug:polymer (Carbopol) ratio 1:1 showed 89\% drug release in $24 \mathrm{hr}$. The release kinetics shows that the release of drug followed zero order release in all the formulation [54].

\section{Gastroretentive approach for sustained release}

One of the most feasible approaches for achieving a prolonged and predictable drug delivery profile in the gastrointestinal tract is to control the gastric residence time (GRT) [55]. Dosage form with a prolonged GRT, that is, gastroretentive dosage forms, provides advantages for drugs having narrow absorption window in the small intestinal region. Furthermore, improve bioavailability is observed for drugs that are absorbed readily on release in the gastrointestinal tract (GIT). These drugs can be delivered ideally by slow release from the stomach [56]. Vadaliya et al. developed gastroretentive drug delivery system of sitagliptin phosphate as the floating microspheres using hydroxypropyl methylcellulose (HPMC) and eudragit RS100 polymers by emulsion solvent evaporation technique. The percentage buoyancy for different formulation was found in the range of 90.5-60.23\%. The drug release was found to be $95.26 \%$ at end of 8 hrs [57]. Gunjal et al. prepared floating tablets of sitagliptin employing different polymers such as guar gum, Carbopol 940, HPMC, and magnesium stearate by effervescent technique. Sodium bicarbonate and citric acid were incorporated as gas generating agent. Tablets containing guar gum along with HPMC and citric acid showed more floating time and shown $90 \%$ drug release at the end of $18 \mathrm{hr}$ [58]. Mohammed Gulzar et al. designed gastroretentive floating tablets of sitagliptin by direct compression employing polymers such as HPMC K100, polyvinylpyrrolidine and polyacrylic acid, respectively, in various concentrations. In vitro dissolution study was carried out in $\mathrm{pH} 1.2$ buffers. The cumulative percentage drug release of all formulations ranged from $92.96 \%$ to $99.28 \%$ at the end of 12 hrs [59]. Kumari et al. developed gastroretentive floating matrix tablets of sitagliptin by wet granulation method using various polymers, namely, HPMC (K4M, K15 M, and K100M), xanthan gum, and combination of polymers and sodium bicarbonate. The developed formulations had floating lag times below 3 minutes and constantly floated on dissolution medium for more than $12 \mathrm{hrs}$. The optimized formulation remained buoyant and showed a sustained drug release (98\%) for $12 \mathrm{hrs} \mathrm{[60].}$

\section{Multiparticulate microsphere approach for sustained release}

Multiparticulate drug delivery leads to wide and uniform distribution throughout GIT which overcomes localized high concentration of drugs at a specific point. This results in more reproducible drug absorption and reduces local irritation when compared to single-unit dosage form such as non-disintegrating polymeric matrix tablets $[61,62]$. Microsphere carrier systems as a have attracted considerable attention for several years in multiparticulate sustained drug delivery [63,64]. Naresh and Pratyusha, prepared saxagliptin microspheres sustain release by ionotropic gelation technique using sodium alginate $0.5 \%$ to $2 \% \mathrm{w} / \mathrm{v}$ ) as drug release modifier. Increase in the concentration of sodium alginate dispersions increased sphericity, size distribution, flow properties, and mean diameter of the microspheres. The in vitro dissolution data showed sustained release up to $10 \mathrm{hrs}$ [65]. Navaneetha et al. formulated a sustain release microspheres for sitagliptin by employing polymers such as albumin and chitosan. The in vitro drug release studies showed that albumin and chitosan in the ratio of 3:1 and drug:polymer ratio of 1:2 has shown maximum drug release of $83.91 \%$ at the end of $12 \mathrm{hrs}[66]$.

\section{DPP4 inhibitors in combination with other therapeutic agents} Combination drug therapy allows medications of different mechanism of action to produce therapeutic effect at lower than maximum doses of each. When smaller doses of medication with different mechanisms of action are combined, synergistic, or additive pharmacological effects can be achieved and dose-dependent side effects can also be minimized [67-69]. Most of the DPP4 inhibitors were combined with metformin (biguanide antihyperglycemic agent) or sitagliptin 
with simvastatin (HMG-CoA reductase inhibitor) to develop formulations [70].

\section{Multilayer tablet approach in combination therapy}

Multilayer tablets have gained much attention in the development of oral sustained drug delivery. They consist of an active matrix core and one or more layers applied during tableting to achieve modified drug release [71]. These tablets are suitable for sequential release of two drugs in combination, separate two incompatible substances and when the release profiles of the two drugs are different from one another [72]. Srinivas and Chaitanya developed a trilayered tablet of immediate release sitagliptin phosphate layer and sustained release metformin hydrochloride layer. Different formulations of sustained release metformin $\mathrm{HCl}$ tablets were prepared using a combination of hydrophilic polymers such as HPMC K100, HPMC K4M, HPMC K15 M, pH-sensitive polymer Carbopol 971P, retarding polymer ethyl cellulose, and low substituted hydroxypropyl cellulose. Sitagliptin immediate release formulations were prepared using crospovidone, CCS, and SSG as superdisintegrants. The optimized batch showed cumulative percentage drug release of sitagliptin phosphate $99.65 \%$ at 30 minutes and metformin $\mathrm{HCl} 98.72 \%$ at $12 \mathrm{hrs}$ [71]. Margret et al. formulated saxagliptin immediate release $2.5 \mathrm{mg}$ and metformin hydrochloride sustained release $500 \mathrm{mg}$ tablets employing hydroxylpropyl methylcellulose polymer and carmellose sodium polymer. The results of the dissolution study showed maximum release of metformin up to $10 \mathrm{hrs}$ and saxagliptin release within 30 minutes [73]. Prasanthi et al. developed a novel bilayered tablet of sitagliptin and simvastatin used pre-gelatinized starch, potato starch, and SSG. The optimized formulation showed $97.23 \%$ for sitagliptin and $98.32 \%$ for simvastatin drug release at the end of 45 minutes [74]. Vidyadhar et al. developed metformin SR $500 \mathrm{mg}$ and linagliptin $2.5 \mathrm{mg}$ bi-layered tablets. The tablets were prepared using hydroxylpropyl methylcellulose (HPMC $\mathrm{K} 100 \mathrm{M}$ ), sodium alginate, gatti gum as sustained release polymer, and Ludiflash, croscarmellose sodium, SSG, crospovidone as immediate release polymer. The in vitro release of drug from the prepared tablets was able to sustain the release of the drug up to $12 \mathrm{hrs}$ [75].

\section{Multiunit particulate system (MUPS) in combination therapy}

Single-unit formulations contain the active ingredient within the single tablet or capsule, whereas multiple-unit dosage forms comprise of number of discrete particles with different release rate that are combined into one dosage unit [76]. Agrawal et al. developed MUPS for metformin and sitagliptin. Enteric-coated sustained release matrix pellets were formulated for metformin while immediate release pellets were formulated for sitagliptin by extrusion spheronization process. The $8-10 \%$ of coating with eudragit S 100 and L 100-55 was considered optimum for coating of the pellets. The optimized batch showed release of $96.4 \%$ of sitagliptin in $1 \mathrm{hr}$ while $97.3 \%$ of metformin in $12 \mathrm{hrs}$ [77].

\section{CONCLUSION}

Although pre-clinical and clinical studies have been suggesting that DPP4 inhibitors have potential in the management of multifactorial diseases beyond glycemic control, the developed formulation approaches on DPP4 inhibitors are mainly in context with treatment of T2DM. In future there is need of employing newer formulation strategies to develop DPP4 inhibitors formulations, which would all together ameliorate the pharmacological processes to deal with the metabolic syndrome. While designing of formulation approaches, the correlation between mechanism and clinical benefits of DPP4 inhibitors should be properly considered. The multifactorial diseases observed in metabolic syndrome characterized by circadian rhythms could be one of the areas to focus. In recent years, chronotherapy approach gaining attention intended to release the drugs according to the circadian cycle of the diseases. In the future, chronotherapy could be employed and interesting approach to be study in the development of DPP4 inhibitors formulations for the management of metabolic syndrome.

\section{ACKNOWLEDGMENT}

The authors acknowledge Dr. D. Y. Patil Institute of Pharmaceutical Science and Research, Pune, for their support and encouragement.

\section{REFERENCES}

1. VanWormer JJ, Boucher JL, Sidebottom AC, Sillah A, Knickelbine T. Lifestyle changes and prevention of metabolic syndrome in the heart of New Ulm Project. Prev Med Rep 2017;6:242-5.

2. Grundy SM, Cleeman JI, Daniels SR, Donato KA, Eckel RH, Franklin BA, et al. Diagnosis and management of the metabolic syndrome: An American Heart Association/National Heart, Lung, and Blood Institute scientific statement: Executive Summary. Crit Pathw Cardiol 2005;4(17):198-203.

3. Hu G, Qiao Q, Tuomilehto J, Balkau B, Borch-Johnsen K, Pyorala K; DECODE Study Group. Prevalence of the metabolic syndrome and its relation to all-cause and cardiovascular mortality in nondiabetic European men and women. Arch Intern Med 2004;164(10):1066-76.

4. Sattigeri JA, Sethi S, Davis JA, Ahmed S, Rayasam GV, Jadhav BG, et al. Approaches towards the development of chimeric DPP4/ACE inhibitors for treating metabolic syndrome. Bioorg Med Chem Lett 2017;27:2313-8.

5. Gong Q, Rajagopalan S, Zhong J. Dpp4 inhibition as a therapeutic strategy in cardiometabolic disease: Incretin-dependent andindependent function. Int J Cardiol 2015;197:170-9.

6. Edwards KL, Stapleton M, Weis J, Irons BK. An update in incretinbased therapy: A focus on glucagon-like peptide-1 receptor agonists. Diabetes Technol Ther 2012;14(10):951-67.

7. Stonehouse AH, Darsow T, Maggs DG. Incretin-based therapies. J Diabetes 2012;4(1):55-67.

8. Bhavya K, Madhusudan N. Dipeptidyl peptidase-IV: A brief review. Res Rev J Chem 2013;2(3):1-6.

9. Zhi-Xu H, Tianxin Y, Shu-Feng Z. Dipeptidyl peptidase 4 inhibitors for the treatment of Type 2 diabetes mellitus: Focus on efficacy, disposition and safety. Austin J Pharmacol Ther 2013;1(1):1-3.

10. Hainer V, Toplak H, Mitrakou A. Treatment modalities of obesity: What fits whom? Diabetes Care 2008;31 Suppl 2:S269-77.

11. Aronne LJ, Thornton-Jones ZD. New targets for obesity pharmacotherapy. Clin Pharmacol Ther 2007;81(5):748-52.

12. Field BC, Wren AM, Cooke D, Bloom SR. Gut hormones as potential new targets for appetite regulation and the treatment of obesity. Drugs 2008;68(2):147-63.

13. Mentlein R, Dahms P, Grandt D, Krüger R. Proteolytic processing of neuropeptide $\mathrm{Y}$ and peptide YY by dipeptidyl peptidase IV. Regul Pept 1993;49(2):133-44.

14. Mentlein R, Gallwitz B, Schmidt WE. Dipeptidyl-peptidase IV hydrolyses gastric inhibitory polypeptide, glucagon-like peptide-1(7-36) amide, peptide histidine methionine and is responsible for their degradation in human serum. Eur J Biochem 1993;214(3):829-35.

15. Stephan M, Radicke A, Leutloff S, Schmiedl A, Pabst R, von Hörsten S, et al. Dipeptidyl peptidase IV (DPP4)-deficiency attenuates dietinduced obesity in rats: Possible implications for the hypothalamic neuropeptidergic system. Behav Brain Res 2011;216(2):712-8.

16. Blüher M. Adipokines - Removing road blocks to obesity and diabetes therapy. Mol Metab 2014;3(3):230-40.

17. Röhrborn D, Eckel J, Sell H. Shedding of dipeptidyl peptidase 4 is mediated by metalloproteases and up-regulated by hypoxia in human adipocytes and smooth muscle cells. FEBS Lett 2014;588(21):3870-7.

18. Röhrborn D, Brückner J, Sell H, Eckel J. Reduced DPP4 activity improves insulin signaling in primary human adipocytes. Biochem Biophys Res Commun 2016;471(3):348-54

19. Stoffers DA, Kieffer TJ, Hussain MA, Drucker DJ, Bonner-Weir S, Habener JF, et al. Insulinotropic glucagon-like peptide 1 agonists stimulate expression of homeodomain protein IDX-1 and increase islet size in mouse pancreas. Diabetes 2000;49(5):741-8.

20. Perfetti R, Zhou J, Doyle ME, Egan JM. Glucagon-like peptide-1 induces cell proliferation and pancreatic-duodenum homeobox-1 expression and increases endocrine cell mass in the pancreas of old, glucose-intolerant rats. Endocrinology 2000;141(12):4600-5.

21. Pannacciulli N, Ducson NT, Salbe AD, Kewei C, Eric MR, Pietro AT, et al. Postprandial glucagon-like peptide-1 (GLP-1) response is positively associated with changes in neuronal activity of brain areas implicated in satiety and food intake regulation in humans. Neuroimage 2007:35(2):511-7

22. Yu JH, Kim MS. Molecular mechanisms of appetite regulation. Diabetes Metab J 2012;36(6):391-8. 
23. Ben-Shlomo S, Zvibel I, Shnell M, Shlomai A, Chepurko E, Halpern Z, et al. Glucagon-like peptide-1 reduces hepatic lipogenesis via activation of AMP-activated protein kinase. J Hepatol 2011;54(7):1214-23.

24. Lee EY, Kim YW, Oh H, Choi CS, Ahn JH, Lee BW, et al. Anti-obesity effects of KR-66195, a synthetic DPP-IV inhibitor, in diet-induced obese mice and obese-diabetic ob/ob mice. Metabolism 2014;63(6):793-9.

25. Fukuda-Tsuru S, Kakimoto T, Utsumi H, Kiuchi S, Ishii S. The novel dipeptidyl peptidase-4 inhibitor teneligliptin prevents high-fat dietinduced obesity accompanied with increased energy expenditure in mice. Eur J Pharmacol 2014;723:207-15.

26. Leenen R, van der Kooy K, Seidell JC, Deurenberg P, Koppeschaar HP. Visceral fat accumulation in relation to sex hormones in obese men and women undergoing weight loss therapy. J Clin Endocrinol Metab 1994;78(6):1515-20

27. Sameshima A, Wada T, Ito T, Kashimura A, Sawakawa K, Yonezawa R, et al. Teneligliptin improves metabolic abnormalities in a mouse model of postmenopausal obesity. J Endocrinol 2015;227(1):25-36.

28. Monami M, Lamanna C, Desideri CM, Mannucci E. DPP-4 inhibitors and lipids: Systematic review and meta-analysis. Adv Ther 2012;29(1):14-25.

29. Monami M, Vitale V, Ambrosio M, Bartoli N, Toffanello G, Ragghianti B, et al. Effects on lipid profile of dipeptidyl peptidase 4 inhibitors, pioglitazone, acarbose, and sulfonylureas: Meta-analysis of placebo controlled trials. Adv Ther 2012;29(9):736-46.

30. Aoki K, Ijima T, Kamiyama H, Kamiko K, Terauchi Y. Anagliptin decreases serum lathosterol level in patients with Type 2 diabetes: A pilot study. Expert Opin Pharmacother 2015;16(12):1749-54.

31. Yano $\mathrm{W}$, Inoue $\mathrm{N}$, Ito $\mathrm{S}$, Itou $\mathrm{T}$, Yasumura $\mathrm{M}$, Yoshinaka $\mathrm{Y}$, et al. Mechanism of lipid-lowering action of the dipeptidyl peptidase-4 inhibitor, anagliptin, in low-density lipoprotein receptor-deficient mice. J Diabetes Investig 2017;8(2):155-60.

32. Matsubara J, Sugiyama S, Sugamura K, Nakamura T, Fujiwara Y, Akiyama E, et al. A dipeptidyl peptidase-4 inhibitor, des-fluorositagliptin, improves endothelial function and reduces atherosclerotic lesion formation in apolipoprotein E-deficient mice. J Am Coll Cardiol 2012;59(3):265-76.

33. Nakagami H, Pang Z, Shimosato T, Moritani T, Kurinami H, Koriyama $\mathrm{H}$, et al. The dipeptidyl peptidase-4 inhibitor teneligliptin improved endothelial dysfunction and insulin resistance in the SHR/NDmcr-cp rat model of metabolic syndrome. Hypertens Res 2014;37(7):629-35

34. Jixin Z, Xiaoquan R, Rajagopalan S. An emerging role of dipeptidyl peptidase 4 (DPP4) beyond glucose control: Potential implications in cardiovascular disease. Atherosclerosis 2012;1:1-10.

35. Singh TP, Vangaveti VN, Malabu UH. Dipeptidyl peptidase-4 inhibitors and their potential role in the management of atherosclerosis - A review. Diabetes Metab Syndr 2015;9(4):223-9.

36. Okuda Y, Omoto S, Taniura T, Shouzu A, Nomura S. Effects of teneligliptin on PDMPs and PAI-1 in patients with diabetes on hemodialysis. Int J Gen Med 2016;9:65-71.

37. Hirano T, Yamashita S, Takahashi M, Hashimoto H, Mori Y, Goto M. Anagliptin, a dipeptidyl peptidase-4 inhibitor, decreases macrophage infiltration and suppresses atherosclerosis in aortic and coronary arteries in cholesterol-fed rabbits. Metabolism 2016;65(6):893-903.

38. Tschöpe D, Hanefeld M, Meier JJ, Gitt AK, Halle M, Bramlage P, et al. The role of co-morbidity in the selection of antidiabetic pharmacotherapy in Type-2 diabetes. Cardiovasc Diabetol 2013;12:62.

39. FDA. Guidance for Industry: Diabetes Mellitus - Evaluating Cardiovascular Risk in New Anti-Diabetic Therapies to Treat Type 2 Diabetes; 2008. Available from: http://www.fda.gov/downloads/Drugs/ GuidanceComplianceRegulatoryInformation/Guidances/ucm071627. pdf. [Last accessed on 2017 Mar 19].

40. Fisman EZ, Tenenbaum A. Antidiabetic treatment with gliptins: focus on cardiovascular effects and outcomes. Cardiovasc Diabetol 2015; $14: 129$

41. Tahara N, Yamagishi SI, Bekki M, Kodama N, Nakamura T, Sugiyama $\mathrm{Y}$, et al. Anagliptin, a dipeptidyl peptidase-4 inhibitor ameliorates arterial stiffness in association with reduction of remnant-like particle cholesterol and alanine transaminase levels in Type 2 diabetic patients. Curr Vasc Pharmacol 2016;14(6):552-62.

42. Nyol S, Gupta M. Immediate drug release dosage form: A review. J Drug Deliv Ther 2013;3(2):155-61.

43. Deshmukh H, Chandrashekhara N, Murade A, Usgaunkar S. Superdisintegrants: A recent investigation and current approach. Asian J Pharm Technol Innov 2012;2:19-25.

44. Rina A, Effionora A, Retnosari A, Hanafi M. Formulation of orodispersible tablet of Luffa acutangula (1) Roxb using novel co-processed via spray dried excipients. Int J Pharm Pharm Sci 2015;7(1):124-9.

45. Iswariya $\mathrm{V}$, Rao $\mathrm{P}$, Babu $\mathrm{V}$, Rao A. Formulation and evaluation of oro dispersive tablets of saxagliptin. Int J Pharm Sci Rev Res 2015;30(2):230-4

46. Debnath M, Kumar A, Dharmaraju M. Formulation, development and in-vitro release kinetics of linagliptin tablet using different super disintegrating agents. J Pharm Sci 2015;4(3):12-25.

47. Shakya S. Formulation and optimization of immediate release tablet of sitagliptin phosphate using response surface methodology. Int J Pharm Bio Med Sci 2015;4:7-12.

48. Wale K, Salunkhe K, Sayyed SF, Chaudhari SR, Bhujbal SS Formulation, development and in vitro evaluation of immediate release tablet of sitagliptin phosphate monohydrate. World J Pharm Res 2014;3(3):4945-57.

49. Jung E, Kim J, Kim SH, Kim S, Cho MH. Gemigliptin, a novel dipeptidyl peptidase-4 inhibitor, exhibits potent anti-glycation properties in vitro and in vivo. Eur J Pharmacol 2014;744:98-102.

50. Dash T, Verma P. Matrix tablets: An approach towards oral extended release drug delivery. Int J Pharm Res Rev 2013;2(2):12-24.

51. Nelson K, Varadarajan P, Chikkanna N, Prakasam K. Development and evaluation of oral controlled release matrix tablets of lamivudine: Optimization and in vitro-in vivo studies. Int $\mathrm{J}$ Pharm Pharm Sci 2015;7(1):95-101

52. Kolli S, Dharavatu P, Sravani R, Reddy S, Kumar V. Formulation and evaluation of vildagliptin sustained release matrix tablets. Int J Curr Pharm Res 2014;6(4):69-75.

53. Kumar GY, Sreekanth J, Satyavati D. Formulation development and evaluation of sustained release matrix tablets of vildagliptin - Synthetic and natural polymers. Asian J Pharm 2015;9(4):26-33.

54. Martha S, Sagarika CH, Nandini K, Seshavardhan V, Kranthi M. Development and in-vitro characterisation of oral sustained release matrix tablets of gemigliptin. Int J Pharm Sci Res 2016;7(9):3770-80

55. Gutierrez-Rocca J, Omidian H, Shan K. Progresses in gastroretentive drug delivery systems. Drug Deliv Oral 2003;23:152-6.

56. Garg S, Sharma S. Gastroretentive drug delivery sytems. Drug Deliv Oral 2003;20:160-6.

57. Vadaliya SK, Vadaliya KR, Desai HT, Patel JK. Formulation and in-vitro evaluation of floating microspheres of anti-diabetic drug prepared by solvent evaporation method. Int J Pharm Chem Sci 2013;2(1):397-403.

58. Gunjal T, Rangari N, Chaudhari S, Bhuktar D. Formulation development and evaluation of sitagliptin floating tablets containing natural polymer. Int J Pharm Pharm Res 2015;3(2):131-41.

59. Gulzar AM, Sanjana A, Vangapandu R. Design and optimization of gastroretentive drug delivery system of sitagliptin. Int J Pharm Sci Res 2016;7(5):2187-93

60. Kumari S, Kumar R, Yamunappa A, Shetty P, Suvarna P, Swamy VB. Formulation and evaluation of gastro retentive matrix tablets of sitagliptin. Asian J Res Pharm Sci 2016;6(1):1-4

61. Sam MT, Gayathri DS, Prasanth V, Vinod B. NSAIDs as microspheres. Int J Pharmacol 2008;6:1.

62. Devrim B, Canefe K. Preparation and evaluation of modified release ibuprofen microspheres with acrylic polymers (Eudragit) by quasiemulsion solvent diffusion method: Effect of variables. Acta Pol Pharm 2006;63(6):521-34.

63. Khan S. Microspheres: A review. World J Pharm Pharm Sci 2012;1(1):125-45

64. Alagusundaram M, Chetty CM, Umashankari K, Attulari B, Lavanya C, Ramakanth S. Microspheres as a novel drug delivery system - A review. Int J ChemTech Res 2009;1(3):526-34

65. Naresh NS, Pratyusha A. Formulation design and evaluation of saxagliptin sustained release microspheres. Indo Am J Pharm Sci 2016;3(6):627-36

66. Navaneetha K, Ramakrishna CH, Chinnala K, Reddy B. Formulation development and in-vitro characterization of sitagliptin microspheres. World J Pharm Res 2016;5(9):1756-67.

67. Pathak N, Kumar A, Methkar V, Pant P, Rao RT. Formulation and optimization of immediate release tablet of an anti-alcoholic drug by dry granulation method. Int J Compr Pharm 2011;2(3):1-4.

68. Shilpa SK, Kumar AM, Garigeyi P. Formulation and optimization of clopidogrel bisulfate immediate release tablet. Int J Pharm Chem Bio Sci 2012;2(1):38-51.

69. Deepak G, Rahul R, Senthil A, Uday S. Formulation and evaluation of irbesartan immediate release tablets. Int Res J Pharm 2012;3(4):410-5

70. Ramadan WH, Kabbara WK. Sitagliptin/Simvastatin:Afirst combination tablet to treat Type 2 diabetes and hypercholesterolemia - aAreview of its characteristics. Vasc Health Risk Manag 2015;11:125-32. 
71. Srinivas P, Chaitanya N. Formulation and evaluation of sitagliptin phosphate and metformin hydrochloride trilayered tablets. Int J Drug Deliv 2013;5(1):15-27

72. Patel M, Sockan GN, Kavitha K, Mani T. Challenges in the formulation of bilayered tablets. Int J Pharm Res Dev 2010;2(2):23-35.

73. Margret CR, Palanisamy P, Jaykar B, Venkateswarlu BS, Pasupathi A. Formulation and evaluation of saxagliptin immediate release and metformin hydrochloride sustained release tablet. Int J Health Sci 2013;1(1):36-52.

74. Prasanthi S, Prasad A, Kumar G, Babu R, Sudhir M, Babu P.
Formulation and evaluation of sitagliptin phosphate and simvastatin bilayered tablets. Indo Am J Pharm Res 2015;5(8):3654-66.

75. Vidyadhari K, Sharma JV, Ramteja YV, Ramesh CH, Pasha M, Kumar M, et al. Formulation and evaluation of linagliptin and metformin bilayer tablets. Int J Adv Pharm Sci 2016;7(2):3072-8.

76. Reddy S, Das P, Das H. MUPS (multiple unit pellet system) tablets - A brief review. J Pharm Biomed Sci 2011;12(2):1-5

77. Agrawal S, Joshi K, Gaud R. Formulation development of multi unit particulate system (MUPS) for anti-diabetic drugs. Asian J Pharm Sci 2015;11(1):77-8 